\title{
Evaluation of Posidonia oceanica Map Generated by Sentinel-2 Image: Gülbahçe Bay Test Site
}

\author{
Güzel Yücel-Gier ${ }^{1, *} \mathbb{D}^{0}$, Güven Koçak ${ }^{2}$, Barış Akçalı ${ }^{1}$, Tarık Illhan ${ }^{1}$, Muhammet \\ Duman $^{1}$
}

${ }^{1}$ Dokuz Eylul University, Institute of Marine Sciences and Technology, Izmir, Turkey

${ }^{2}$ izmir Katip Çelebi University Department of Geomatics Engineering, izmir, Turkey

\section{Article History}

Received 30 October 2019

Accepted 03 February 2020

First Online 07 February 2020

\section{Corresponding Author}

Tel.: +902322785565

E-mail: yucel.gier@deu.edu.tr

\section{Keywords}

Remote sensing

Sentinel-2

P. oceanica

Water transparency

Secchi disk depth

\begin{abstract}
Remote Sensing offers an effective and low-cost solution for mapping the extent of seagrasses and temporally monitoring them routinely. In an in-situ well-explored Gülbahçe Bay test site, we used a high-resolution Sentinel-2 image to map the distribution of P. oceanica. Atmospheric and water column corrections were applied to the raw image. Thematic maps of the area were obtained by supervised classification and their accuracy was evaluated by cross-validation. The produced maps were also compared to a previously generated high accurate thematic map generated by the combination of sub-bottom profiler, side-scan sonar, and very high-resolution satellite image data. The classification achieved nearly $88 \%$ user accuracy at best. The assessment of the accuracy was also carried out in terms of water transparency. For this purpose, Secchi disk depths (SDDs) over the study area were inverted from the satellite-derived vertical attenuation coefficients by using a model. This model was retrieved by tuning the coefficients to 22 local SDD measurements. Sentinel- 2 twinsatellite with its high spatial and temporal resolution data can contribute to mapping the P. oceanica cover in shallow waters. Their multispectral data can also be utilized for deriving the water transparency in order to determine the application limitations of the generated map.
\end{abstract}

\section{Introduction}

In the Mediterranean marine eco-system Posidonia oceanica (Linnaeus) Delile ( $P$. oceanica), as an endemic species, plays an important role in maintaining the balance of the marine ecosystems(Delgado, Ruiz, Pérez, Romero \& Ballesteros, 1999;Duarte, 2002; Pergent, 2006). The richness of Mediterranean coastal waters is partially formed by seagrass meadows, which cover $20-30 \%$ of the surface area of the seabeds at depths of 0 to 50 meters (Boudouresque et al.,2012).

In addition to the above significant roles, $P$. oceanica plays a key role in carbon sequestration (Fourqurean et al., 2012), in serving as a buffer from coastline erosion (Pergent et al., 2012), in nurseries
(Giannoulaki et al., 2013), in enriching the fishing terrain (Nordlund, Unsworth, Gullström \& Cullen-Unsworth, 2017) and as a bio-indicator (Nordlund et al., 2016). The Mediterranean seagrass meadows are under protection by international conventions and national legislation, i.e., $P$. oceanica is included in the European Union 1992 Habitats Directive (92/43/CEE), a directive that regulates the EU 'Natura 2000 areas' that form part of the coastline of all Mediterranean countries. $P$. oceanica is also included in the Mediterranean Action Plan (UNEP, 2012) and in the annexes of the Bern and Barcelona Conventions (1996). In addition to the afore mentioned, the Republic of Turkey Ministry of Agriculture and Forestry (RTMAF) prohibits the landing, collecting and hunting of seagrass species $P$. oceanica and Zostera 
noltei (Hornemann). This prohibition complies with notification No.4/1 for commercial fishing; notification No. 4/2 and for non-commercial fishing (RTMAF, 2016).

Despite this legislation, these sensitive ecosystems are being damaged by coastal tourism, anchorage, destructive fishing practices (e.g. bottom trawling), uncontrolled development of aquaculture, coastal structures and industrial wastes (Cancemi, DeFalco \& Pergent, 2003; Holmer, Perez \& Duarte, 2003). At the same time due to their extremely slow growth rate (approx. 1-4 cm per year) (Traganos \& Reinartz, 2018a). It may take many years for these meadows to recover.

The direct and indirect consequences of their decline are numerous, both ecological and economical. Another factor is a scarcity of data regarding seagrass meadows which makes it difficult to manage and conserve ecosystems in the region. For the Mediterranean Sea and also for Turkey (Akçalı, Kaboğlu \& Güçlüsoy, 2019) the present data is based on experts' personal knowledge, principally based point-based information (Giannoulaki et al., 2013). In order to conserve coastal marine environments, it is necessary to obtain information on $P$. oceanica to provide background data as indicators of the quality of the environment in question, which needs to be evaluated reliably and urgently. Habitat mapping constitutes a valuable tool in marine spatial planning and coastal management (Piazzi, Acunto \& Cinelli, 2000; Kostylev et al., 2001; Baker \& Harris, 2012). Optical remote sensing methods provide supplementary sources of information for monitoring and mapping seagrass ecosystems. When taking into consideration the large areas and remote locations involved, satellite remote sensing method is both time and cost-effective (Knudby \& Nordlund, 2011; Hossain, Bujang, Zakaria \&Hashim, 2014; Traganos \& Reinartz, 2018a). To this end, several studies have used satellite imagery to map $P$. oceanica distribution (Fornes et al., 2006; Matta et al., 2014; Pasqualini et al., 2005).

The distribution of Mediterranean seagrass meadows has been mapped by a previous study using sub-bottom profiler, side-scan sonar and highresolution Worldview-2 satellite image, in Gülbahçe Bay (İzmir Gulf, Turkey) located in the Eastern Aegean Sea. The results were compared with the control data taken from 926 sites to determine the total area of $P$. oceanica in the Gülbahçe Bay (Yücel-Gier, Kocak, Akçalı, İlhan \& Duman, 2019). In this study, the main objective was to map the distribution of $P$. oceanica in Gülbahçe Bay, a test area, to determine the effectiveness of Sentinel-2 satellite imagery. We classified five previously selected habitat classes, P. oceanica, C. nodosa, sand, hard bottom, and soft bottom in order to produce a thematic map illustrating the existence of $P$. oceanica. Accuracy of the generated map was evaluated by using crossvalidation and its dependency with depth and water transparency was investigated. For cross-validation, the entire field data were divided into two disjoint subsets where the training subset was used to produce the map and the validation subset to evaluate the map accuracy.

\section{Material and Methods}

\section{Study Area}

The Gulf of Izmir is divided, according to its topographical, hydrological and ecological features and into three regions, the Inner, Middle, and Outer. The study area, Gülbahçe Bay, is situated in the outer region of the Izmir Gulf in the Aegean Sea. Our study site here covers a shallow and semi-closed bay extending over an area of $58 \mathrm{~km}^{2}$ (Figure 1a, b). In Gülbahçe Bay there are two meadow species; Posidonia oceanica (Linnaeus) Delile and Cymodocea nodosa (Ucria). The tidal range is about $4 \mathrm{~cm}$ during neap tides and about $17 \mathrm{~cm}$ during springs tides in Izmir Gulf (Alpar, Burak \& Gazioğlu,1997). A crucial factor for choosing Gülbahçe as a study area was the fact that it contains unique natural monuments (UNEP, 2012) including three different $P$. oceanica meadow types; tiger meadows, atolls and barrier reefs (Yücel-Gier et al., 2019).

\section{Image Data}

Sentinel-2 is the satellite system, established to observe the earth under the Copernicus program implemented by the European Commission consist of Sentinel-2A, launched on 23 June 2015, and Sentinel-2B launched on 7 March 2017. Each satellite has a 10-day revisit frequency thus any given region of the earth can be observed every 5 days. The satellites, in a sunsynchronous orbit, are located at $786 \mathrm{~km}$ above the earth so that any particular location can be viewed at identical local solar times. The Sentinel-2's MultiSpectral Imager (MSI) scans the earth's surface in 13 bands of visible, near-infrared (NIR) and shortwave infrared (SWIR) electromagnetic spectrums. MSI provides a spatial resolution of $10 \mathrm{~m}$ in the visible blue, green, red and near-infrared bands, while the remaining bands have a resolution of 20 and $60 \mathrm{~m}$. The radiometric resolution of each MSI band is 12 bits. The image with tile

S2A_MSIL2A_20170304T085841_N0204_R007_T35SM C_20170304T085855 was downloaded from the Sentinel Scientific Data Hub (https://scihub.copernicus.eu/) for use in this study.

This Level $1 \mathrm{C}$ image was taken on the 4 of March 2017 at 4:58:41 UTC with a nadir viewing angle of nearly 4 degrees, covering an area of $100 \mathrm{~km} \times 100 \mathrm{~km}$. A distinctive feature of Level $1 \mathrm{C}$ images is that they are pre-georeferenced and delivered in an orthorectified UTM projection with WGS84 ellipsoid, unlike Level 1B images given in sensor geometry. Sentinel-2 level $1 C$ images are images not corrected for atmospheric effects, haze, etc.

\section{Field Data}

Field data for the project were collected between2014-2016. Multispectral WorldView-2 image 
from March 20, 2012, was taken as the base reference for all data prior to in-situ data collection. Data were collected through direct observations with snorkelling, SCUBA diving or aquatic camera observation. The complete image was explored, and more than 900 individual locations were selected to be evaluated in order to see if data could be compared to in-situ data taken two years later. Based on this data, a total of 449 manually generated polygons (containing 10940 pixels), belonging to five different habitats were used within the scope of this classification (Figure 1c). Five classes were identified as $P$. oceanica, Cymodocea nodosa, hard bottom, mud and sand in the study for further thematic mapping. Bathymetry data were calculated within a previously completed project (Yücel-Gieret al., 2019).
We used Secchi disk depth (SDD) data in the study as a criterion for water transparency in order to present their relation with the classification results. Secchi disk data were taken at 22 different locations on three consecutive days (21-22-23 March 2017) in the Gulf of Izmir where one data location lies within in the study area as shown in Figure1b (IMST, 2017).

\section{Image Analysis Methodology}

Within the scope of the study, coastal aerosol, blue and green bands (B1, B2, and B3) of Sentinel-2 image were used for benthic habitat mapping. The remaining bands having longer wavelengths were not included in the study since they experience more absorption
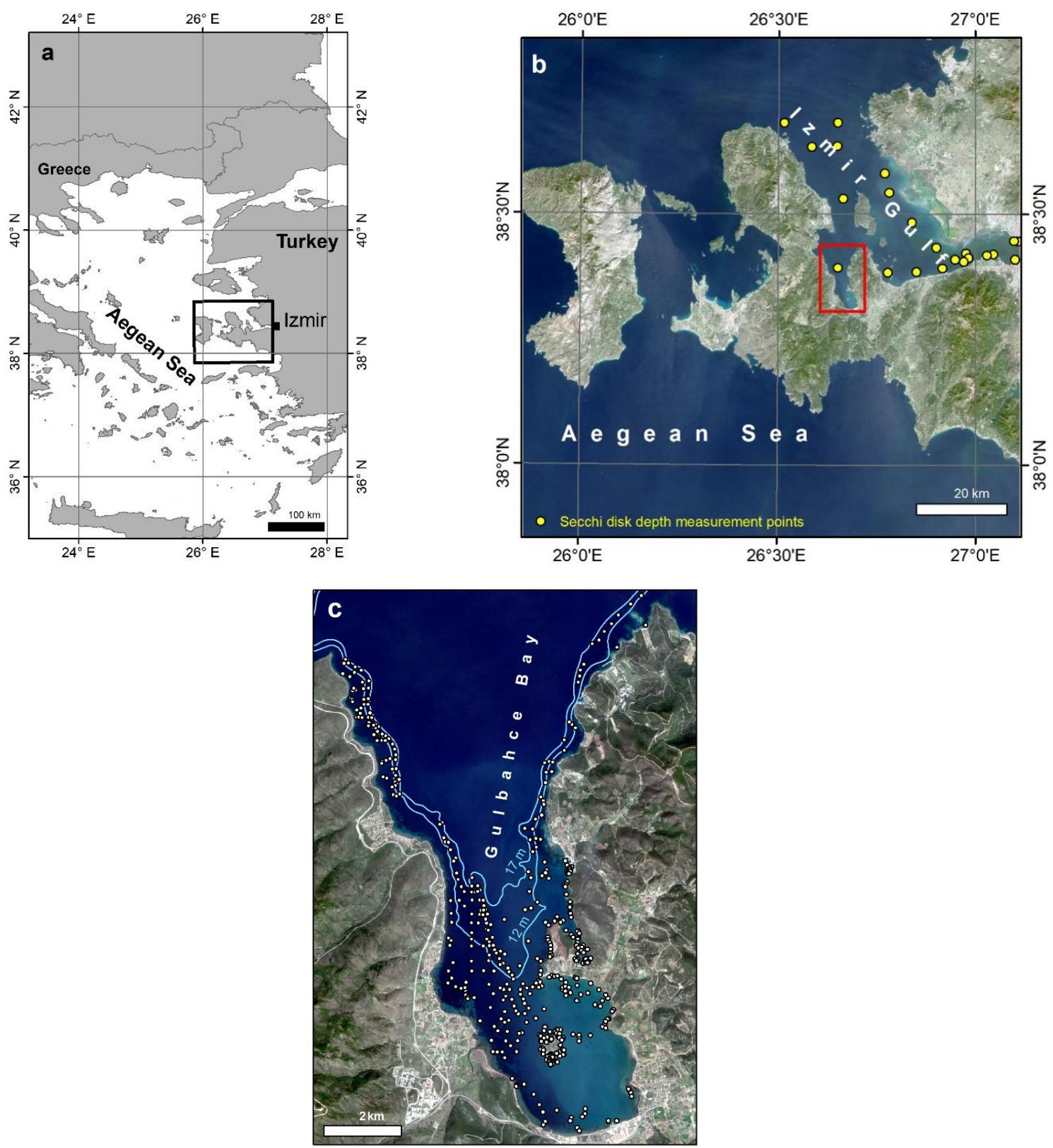

Figure 1. a) General view of Izmir Gulf and its surrounding in the Aegean Sea. Black rectangle shows the downloaded Sentinel2 image's $100 \mathrm{~km} \times 100 \mathrm{~km}$ coverage area. b) zoomed view of the rectangle in a): Red frame denotes the study area and yellow circles indicate Secchi disk depth (SDD) measurement points. These measurements were used to calibrate the satellite-derived vertical attenuation values to SDDs for each pixel by a model function within the entire Gulf. SDDs in the study area were obtained by this model (see Results section). c) The study area; Gülbahçe Bay. White circles show field data locations. 
(Horning, Robinson, Sterling, Turner, \&Spector,2010). The reflectance values of $\mathrm{B} 2$ and $\mathrm{B} 3$ are given at a ground sampling distance (GSD) of $10 \mathrm{~m}$. Therefore, GSD for B1 was resampled from $60 \mathrm{~m}$ to $10 \mathrm{~m}$ by using bilinear interpolation. The European Space Agency's (ESA) software Sentinel Application Platform (SNAP 6.0) was used for this downsampling.

\section{Atmospheric Correction}

Sentinel-2 Level $1 \mathrm{C}$ delivers reflectance values from the top of the atmosphere (TOA). Therefore, atmospheric correction was required to acquire the reflectance at the bottom of the atmosphere (BOA), namely the reflectance from the water surface. Sen2Cor toolbox (v.2.5.5) available under SNAP was used to achieve the correction from TOA to BOA. Sen2Cor calculates the correction for Sentinel-2using a database of 24 look-up tables containing atmospheric conditions observed on earth. Among the parameters, mid-latitude summer atmospheric conditions were selected, and aerosol type was set to rural due to the close proximity of the study area to land. Another parameter, ozone input, was set to automatic to be obtained automatically by the Sen2Cor software. Sun de-glinting was not exercised because no sun-glint was observed on the image.

\section{Masking}

Land pixels were disregarded during the process as the study was based on benthic habitat mapping. For this purpose, land areas were masked out manually by digitizing a georeferenced WorldView-2 image with $2 \mathrm{~m}$ spatial resolution. We also adopted a depth mask of 17 $\mathrm{m}$ since it marked the limit of our $P$. oceanica samples obtained in the field.

\section{Water Column Correction}

In benthic habitat mapping, the water surface reflectance should be corrected for depth effect in order to better identify substrates. This is known as water column correction and the image-based method proposed by Lyzenga (1981) was used in this study. It is based on the assumption that the ratio of the bottom reflectance of an object in two bands is constant for all objects. The depth-invariant $(D I)$ index for each pixel can be obtained for the ith and jth bands by using the water surface and deep water reflectance:

$$
D I_{i j}=\ln \left(R_{i, \text { surface }}-R_{i, \text { deep }}\right)-\frac{k_{i, d}}{k_{j, d}} \ln \left(R_{j, \text { surface }}-R_{j, \text { deep }}\right)
$$

If the atmospheric correction has already been applied to the image, deep water reflectance can be dismissed (Green et al, 2000). The numerical value denoting the ratio of the diffuse attenuation coefficients $\frac{k_{i, d}}{k_{j, d}}$ need be calculated using the reflectance values of the same class sampled at varying depths. Unlike linear regression, where a parameter is taken as an independent variable, the ratio is calculated by treating both variables as independent by means of the following equation (Lyzenga, 1981):

$$
\frac{k_{i, d}}{k_{j, d}}=a+\sqrt{a^{2}+1}
$$

The parameter $a$ in Equation (2) can be obtained with the help of the variances and the covariance of the two bands:

$$
\begin{gathered}
a=\frac{\sigma_{i i}-\sigma_{j j}}{2 \sigma_{i j}} \\
\sigma_{i j}=\operatorname{mean}\left(\boldsymbol{X}_{\boldsymbol{i}} \boldsymbol{X}_{\boldsymbol{j}}\right)-\operatorname{mean}\left(\boldsymbol{X}_{\boldsymbol{i}}\right) \cdot \operatorname{mean}\left(\boldsymbol{X}_{\boldsymbol{j}}\right) .
\end{gathered}
$$

$\boldsymbol{X}_{\boldsymbol{i}}$ and $\boldsymbol{X}_{\boldsymbol{j}}$ in the above equation indicate the vectors in which numerical values $\ln \left(R_{\text {surface }}-\right.$ $R_{\text {deep }}$ )at sampling points are held for the relevant bands.

Samples from the sand class were chosen as reference for the estimation of the ratios in Equation (1) since the sand class can be distinguished more clearly than the other habitat classes. The numerical values were computed for a combination of the bands B1, B2, and $\mathrm{B} 3$.

\section{Supervised Classification and Accuracy Assessment}

To produce a thematic map, mostly the supervised classification method is used where all image pixels are grouped into predefined classes based on the spectral reflectance of a smaller set consisting of ground truth pixels. The producer labels the ground truth pixels belonging to each class upon on-site visiting of selected locations which should be fairly evenly distributed across the whole image. A chosen classifier predicts the classes of the remaining unlabelled pixels by using the information from the relatively small ground truth data set. Among several classifiers, we selected the support vector machine (SVM) method as the classifier to generate the benthic habitat map. SVM is one of the classification methods used for benthic habitat mapping in recent studies (Traganos and Reinartz, 2018a, b; Poursanidis, Traganos, Reinartz \& Chrysoulakis, 2019). As in all classifiers, spectral reflectance values of the ground truth pixels span the $n$-dimensional space where $\mathrm{n}$ denotes the number of bands. In this feature space, two classes are separated from each other by a decision boundary called hyperplane. This hyperplane is estimated by the pixels lying at the margin of the two classes which are termed support vectors. In order to increase the separability between classes, the feature space is projected onto a higher dimensional space by a nonlinear function (kernel function) where a linear hyperplane can be estimated as the decision boundary 
(Richards, 2013). This study employed the LibSVM library available in the EnMAP-Box software (van der Linden et al, 2015) in order to carry out SVM classification. We used a Gaussian radial basis function kernel for projecting the feature space in the classification.

Two different thematic classifications were carried out within the study. The first classification was devised to determine the five different classes in the study area. These classes were identified as $P$. oceanica, $C$. nodosa, sand, hard bottom, and soft bottom. In the second classification, a binary thematic map was obtained with the $P$. oceanica class and the non- $P$. oceanica class.

k-fold cross-validation was used to test the accuracy of the thematic map generated in the study. Here, the number of ground truth pixels for each class was divided by an integer $\mathrm{k}$ to form an approximately equal number of pixels. The classifier was trained by the k-1 subset of pixels where the remaining subset was used for validating the generated solution. The classification was thus repeated $k$ times where each time one of the $k$ subsets was reserved for the validation. In this way, $\mathrm{k}$ user and producer accuracies were obtained for each of the classes.

\section{Vertical Attenuation Coefficient}

The accuracy of the benthic habitat classification depends on the power of the light coming from the substrates. Apart from atmospheric conditions, the optical properties of the water determine the amount of photon flux onto the sensor. Two types of optical properties can be identified: Inherent optical properties (IOPs) depend only on the medium and will be given with absorption and scattering coefficients. Apparent optical properties (AOPs) depend not only on the medium but also on the geometric (directional) structure of the light field. They define radiometric quantities like downwelling and upwelling radiances (Mobley, 1994).

The downward plane irradiance at depth $z$ for a band with wavelength $\lambda$ can be modeled with

$$
E_{d}(z, \lambda)=E_{d}(0, \lambda) e^{-K_{d} Z}
$$

where $E_{d}(0, \lambda)$ denotes the irradiance at the water surface. Equation (3) models the decay of the irradiance from the water surface to an increasing depth z. $K_{d}$ is defined as the vertical attenuation coefficient which specifies the speed of the decay. Increasing $K_{d}$ will result in less irradiance from deeper layers of the water and thus in lesser penetration of the incoming light.

In this study, we utilized the vertical attenuation coefficient obtained by the C2RCC processor in order to relate the classification accuracy to the light penetration in the coastal environment. C2RCC (Case 2 Regional CoastColour) is a processor which can deliver the attenuation coefficient $K_{d}(\lambda=489)$ at each image pixel together with the IOP coefficients. It also provides the minimum of the three attenuation coefficients ( $\min K_{d}$ ) in the first three bands having the least wavelengths of the Sentinel-2 bands. C2RCC is a neural network-based processor into which TOA reflectance will be fed. Neural networks are trained by using a large database of simulated water leaving radiances and related TOA radiances. Hydrolight model is used for inwater modelling (Brockmann, Doerffer, Peters, Kerstin, Embacher \& Ruescas, 2016).

\section{Results}

\section{Image Processing}

Atmospheric correction was applied to the raw Sentinel-2 level $1 \mathrm{C}$ image and the level $2 \mathrm{~A}$ corrected image referring to the bottom of the atmosphere (BOA) was obtained. The implementation of the correction greatly reduced the cloud and haze present on the entire tile which resulted in a clear improvement especially in the northern and eastern parts of the tile. Compared to the raw image, reflectance from the seabed was more pronounced in areas close to the shore.

For obtaining the DI composite, the ratios of the diffuse attenuation coefficients were computed by using sand class reflectance samples. We treated the logtransformed reflectance as independent variables and estimated the ratios to be $0.45,0.30$ and 0.72 by using the Equation (2) for B1/B2, B1/B3, and B2/B3, respectively. Those ratio values were then used for computing the depth-invariant (DI) indices over the whole image pixel location by the Equation (1).

\section{Accuracy Assessment}

The three images obtained in this study were subjected to supervised classification based on ground truth data. The initial data is the intact Level $1 \mathrm{C}$ image of the TOA downloaded from the Sentinel Data Hub without any correction. The second image is the BOA image obtained by applying the atmospheric correction to the Level $1 \mathrm{C}$ image. The last one is a DI composite that is obtained by applying water column correction with the three band-ratios. These images were classified for producing the thematic maps of two sets containing five and two cover types, respectively. The classifications were repeated on the three images of each set and they will be denoted hereafter as 5-class and binary classifications.

We carried out 6-fold cross-validation for accuracy evaluation on each of the six solutions. Table 1 shows the accuracy results. While classifying the Level $2 \mathrm{~A}$ image produced the largest overall accuracy (OA) for the 5class case, the binary map generated by raw Level $1 C$ image showed the highest OA score. The largest $P$. oceanica user and producer accuracies (UA, PA) were also obtained with the same images. Pairwise differences between the $P$. oceanica UA values of the 
three images were tested for the significance by using a t-test for two population means with unknown and unequal variances (Kanji, 2006). The tests were performed separately for each of the 5-class and binary cases. All three UAs differ from each other at a $5 \%$ significance level for the classifications carried out with five cover types. UAs acquired with Level $1 \mathrm{C}$ and Level 2A images with binary classification showed no significant difference. DI composites produced the least UAs for both 5-class and binary cases.

Thematic maps produced by classification were assessed based on the ground truth data points inside polygons distributed sparsely over the study area. This allows only a limited evaluation of the classification results at discrete locations. A total of 10490 pixel locations were used for PA and UA calculations in approximately $29.2 \mathrm{sq} \mathrm{km}$ process area bounded by a $17 \mathrm{~m}$ depth mask. These pixels were included inside 449 polygons which correspond to a distribution density of some 15 polygons/sq km. For a more continuous and uniform comparison of the classification results, we used an existing thematic ground truth map. This reference map was generated by the synergistic combination of WorldView-2 image classification, subbottom profiler, and side-scan sonar data within a project (Yücel-Gier et al., 2019). The comparisons were carried out for six image classification maps. Prior to comparison, each map was low-pass filtered by using a $5 \times 5$ pixel kernel size and isolated pixels were removed with 8-pixel connectivity. The comparisons revealed that Level 2A binary classification achieved the best UA with 87.9\% whereas $2.2 \%$ lower UA was acquired by the classification with 5 cover types. Eliminating the depth effect with the DI index did not improve the accuracies for both 5-class and binary classifications, which have the worst numerical values amongst all. Accuracy values agree with the PAs rather than the UAs given in Table 1. The PAs were greater than UA because a larger set of ground truth data were used for training the classifier in k-fold cross-validation.

Figure2a shows the Level 2A binary map and Figure $2 b$ displays the distribution of false positives (FPs) and false negatives (FNs) extracted by differencing the binary map and the ground truth map. FPs denote the

Table 1. Classification accuracies using ground truth data (the highest OA and UA values are given in bold)

\begin{tabular}{|c|c|c|c|c|c|c|}
\hline \multirow{2}{*}{$\begin{array}{l}\text { with five cover types } \\
\text { Classes }\end{array}$} & \multicolumn{2}{|c|}{ S2 Level $1 C$} & \multicolumn{2}{|c|}{ S2 Level $2 A$} & \multicolumn{2}{|c|}{ DI Composite } \\
\hline & $U A$ & $P A$ & $U A$ & $P A$ & $U A$ & $P A$ \\
\hline P. oceanica & $79.7 \pm 0.36$ & $83.8 \pm 0.40$ & $80.6 \pm 0.36$ & $84.1 \pm 0.40$ & $78.2 \pm 0.39$ & $79.8 \pm 0.41$ \\
\hline C. nodosa. & $43.8 \pm 0.43$ & $26.8 \pm 3.26$ & $35.6 \pm 0.46$ & $31.8 \pm 2.49$ & $35.3 \pm 0.46$ & $33.8 \pm 2.41$ \\
\hline Hard bottom & $70.6 \pm 0.48$ & $58.3 \pm 3.73$ & $64.5 \pm 0.49$ & $54.2 \pm 3.84$ & $44.6 \pm 0.49$ & $51.4 \pm 3.17$ \\
\hline Sand & $51.9 \pm 0.42$ & $75.1 \pm 1.49$ & $59.0 \pm 0.46$ & $65.4 \pm 1.78$ & $60.8 \pm 0.47$ & $61.1 \pm 1.97$ \\
\hline Soft bottom & $72.7 \pm 0.46$ & $65.9 \pm 0.65$ & $74.2 \pm 0.45$ & $69.2 \pm 0.63$ & $68.9 \pm 0.46$ & $66.3 \pm 0.63$ \\
\hline $\mathrm{OA}$ & \multicolumn{2}{|c|}{75.1} & \multicolumn{2}{|c|}{76.1} & \multicolumn{2}{|c|}{72.6} \\
\hline with binary cover types & $U A$ & $P A$ & $U A$ & $P A$ & $U A$ & $P A$ \\
\hline P. oceanica & $78.0 \pm 0.34$ & $85.5 \pm 0.39$ & $77.4 \pm 0.34$ & $85.8 \pm 0.39$ & $76.1 \pm 0.37$ & $82.6 \pm 0.40$ \\
\hline Non-P. oceanica & $78.7 \pm 0.45$ & $69.0 \pm 0.55$ & $78.9 \pm 0.46$ & $67.8 \pm 0.56$ & $75.0 \pm 0.46$ & $66.7 \pm 0.57$ \\
\hline $\mathrm{OA}$ & & & & & & \\
\hline
\end{tabular}

$\mathrm{OA}=$ Overall Accuracy, $\mathrm{PA}=$ Producer Accuracy, UA = User Accuracy

All numbers are given in percentages. The error term is standard deviation.
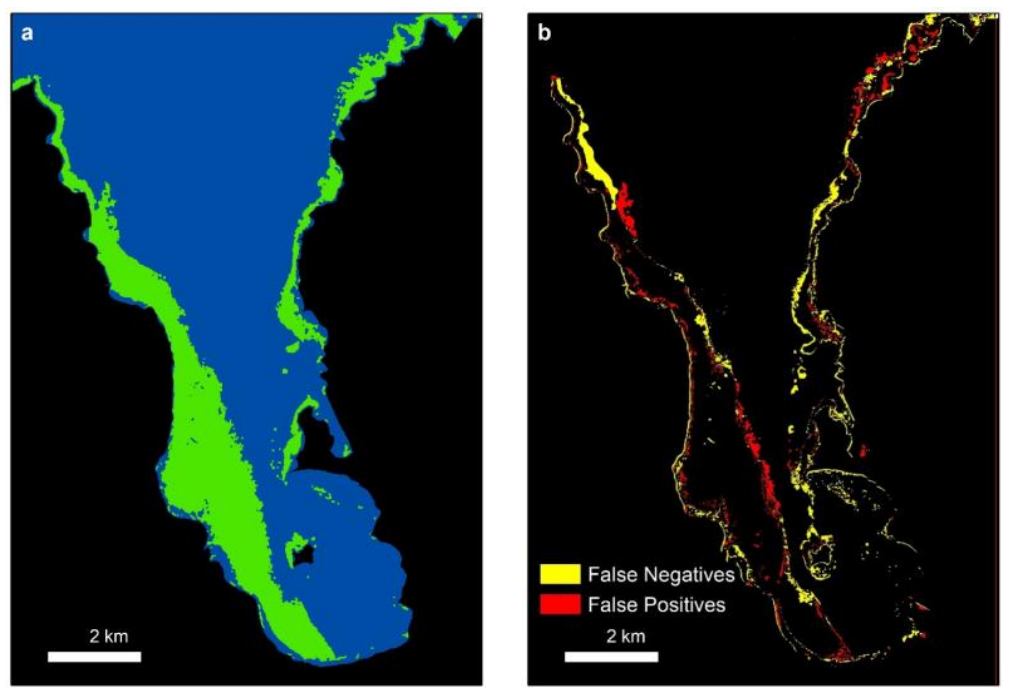

Figure 2. a) Filtered binary map obtained by the classification of the Sentinel-2 Level 2A image, b) comparison of the map-a with an existing ground truth thematic map. FNs show pixels where the classifier could not detect. FPs show the locations of incorrectly detected pixels. 
incorrectly labelled pixels though not available in the ground truth map. FNs, on the other hand, are true $P$. oceanica locations that were not revealed by the classifier. The black background other than land mask displays correctly classified true positives (TPs: $P$. oceanica) and true negatives (TNs: non-P. oceanica). The density of the erroneous pixels increases to the boundary of $P$. oceanica covers.

\section{Variation of accuracy with depth and water transparency}

We now examine how the accuracy varies with depth and water transparency. The analysis will give insight into the light penetration condition in the study area and its impact on classification accuracy. Hereafter the raw unfiltered binary map obtained by the Level 2A image classification will be used for the analysis.

The bar plot in Figure3a shows the relation between the number of $P$. oceanica ground truth pixels and the depth at which these pixels are located. Nearly two-thirds of all $P$. oceanica ground truth pixels were sampled at depths between 0-10 m. Above $10 \mathrm{~m}$, the number of $P$. oceanica populations begin to decrease. The sharp decrease in the number of the samples of about 50\% from 8-10 interval to 10-12 interval explains that less P. oceanica pixels could be identified in the Sentinel-2 image at depths greater than $10 \mathrm{~m}$. At 16-17 $\mathrm{m}$ interval, only 36 samples were collected which correspond to $0.6 \%$ of all $P$. oceanica ground truth pixels.

In order to show the change of the classification accuracy with depth, the number of correctly classified $P$. oceanica pixels in each $1 \mathrm{~m}$ depth interval was divided into the total number of $P$. oceanica pixels in that interval. In this way, true positive (TP) values for $P$. oceanica class were computed for each interval. Cumulative TP (CTP) was calculated likewise but referred to the interval beginning from zero to the depth explored (Figure3a). At 0-1 m interval, 82.9\% TP was achieved. The TP in $1 \mathrm{~m}$ interval increased to $96.5 \%$ at 8 $\mathrm{m}$ depth, the largest of all TPs. Beginning from $8 \mathrm{~m}$, TP fell to lower values and it became $33.3 \%$ in the $16-17 \mathrm{~m}$ interval. CTP, on the other hand, increased to its maximum $92.0 \%$ at the end of $8 \mathrm{~m}$ depth and after this point, it showed a smooth constant decline resulting in the overall CTP of $86.3 \%$. This value is within the confidence interval of the PA in Table 1 for the Level 2A binary map, which was adopted for the analysis.

In this study, we also investigated whether the classification accuracy is associated with the light transmittance of the benthic habitat. For this purpose, we used the vertical attenuation coefficient $\left(K_{d}\right)$ which was derived by the C2RCC processor. This processor can deliver among several IOPs and AOPs the minimum of the vertical attenuation coefficients of the Sentinel-2's B1, B2, and B3 bands. The lowest $K_{d}$ of the three bands at a pixel location is denoted here as $\min K_{d}$. In order to use image-derived, pixel-based $K_{d}$ values, their relationship with the field must be examined. We calibrated $\min K_{d}$ values to the SDD measurements made at 22 locations distributed in the Izmir Gulf (Figure 1b). A power model was fitted to the data set (Alikas \& Kratzer, 2017) and the model function was obtained as

$$
y=3.373 x^{-0.5211}
$$

Measured SDDs can thus be explained by the $\min K_{d}$ derived by C2RCC at $89 \%$ (Figure4a). SDD for any location can be computed by putting the $\min K_{d}$ value at the right-hand side of eq. (4).

For the analysis of the SDD variation with depth, we calculated the SDDs in Equation (4) (herein denoted as computed SDD) by using $\min K_{d}$ values at 449 ground truth polygon centers. The depths of these polygon centers were plotted against the computed SDDs in
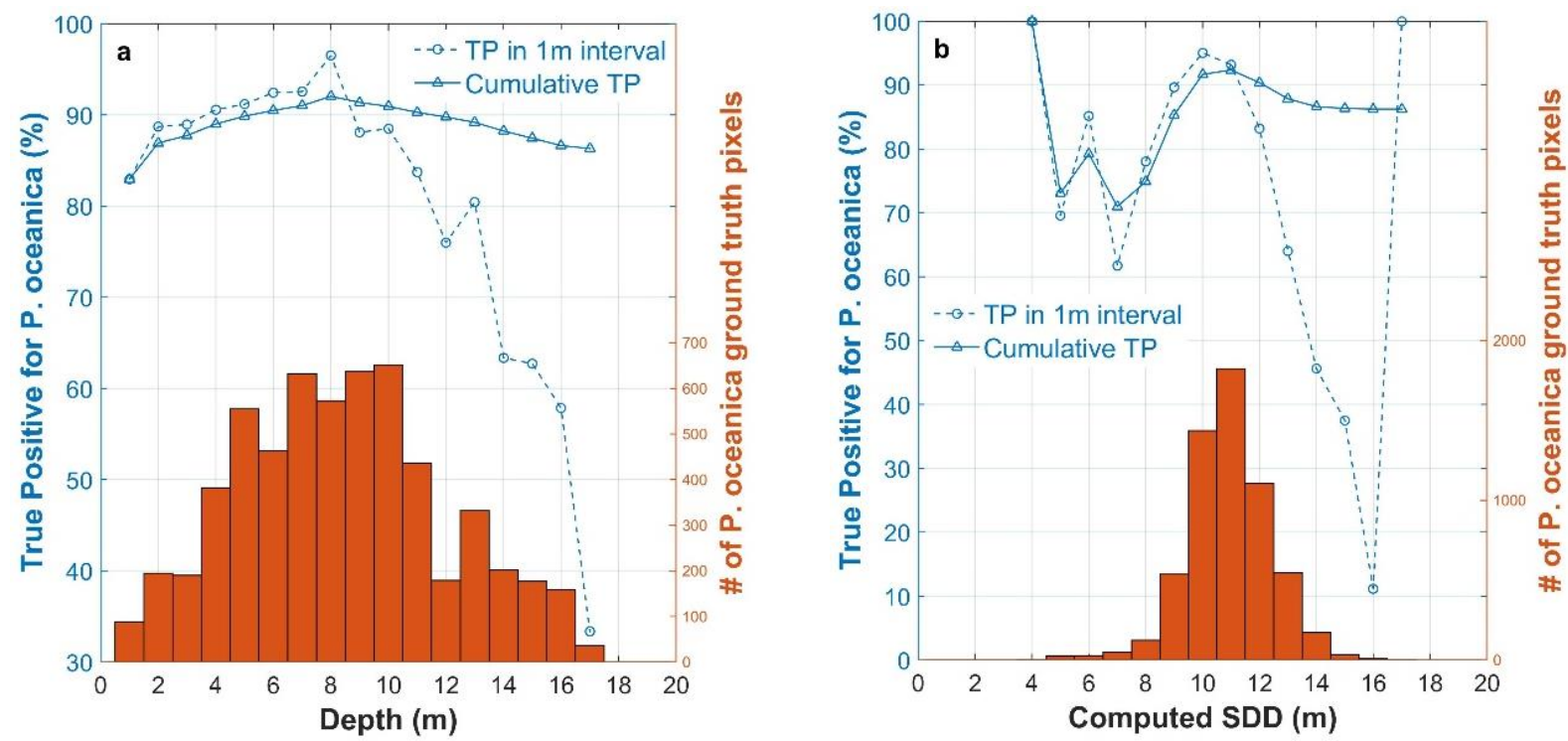

Figure 3. a) Variation of accuracies with bathymetric depth and b) with SDD. Bar plots show the number of pixels in $1 \mathrm{~m}$ intervals. 
Figure4b. Computed SDDs increase with increasing sample depth and reach a plateau. Although the depths of the samples increase computed SDDs fluctuate around a nearly constant value. A proper model must be fitted to the point field in order to compute this limit value. Among several models, a second-order polynomial was adopted. The least-squares estimator with robust bisquare method was used for reducing the effect of outlying points. The model function is given as

$$
y=-0.02792 x^{2}+0.8549 x+5.50
$$

The numerical value at which the depth and the computed SDD are identical was obtained by solving the roots of Equation (5).

Figure3b gives the variation of $P$. oceanica classification accuracy depending on the SDDs. No samples fell into the 0-3 $\mathrm{m}$ interval. The largest samples came from 10-11 m SDD, nearly one-third of all $P$. oceanica ground truth pixels. TPs were extremely

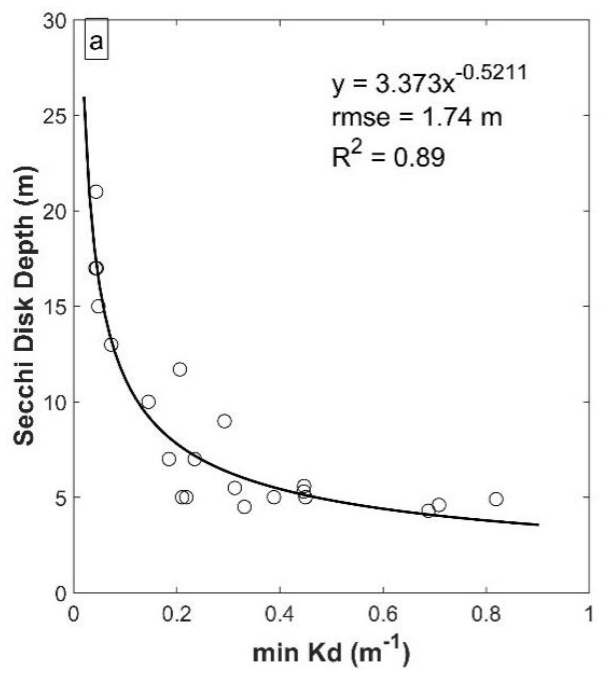

variable in the interval between $3 \mathrm{~m}$ to $8 \mathrm{~m}$ SDDs and they correlate strongly with the number of pixels. The maximum CTP accuracy was obtained at $11 \mathrm{~m}$ SDD with $92.4 \%$ which dropped to the overall value of $86.3 \%$. Figure 3 a and 3bshow the dependency of TPs and CTPS of $P$. oceanica ground truth pixels against the bathymetry and the computed SDD, respectively. The graphics depict the accuracy variation in a single variable and for example, a selected depth includes the contribution of pixels from different SDDs having the same depth. Classification accuracy can be better understood when the TPs are investigated in both variables. The color matrix in Figure5a illustrates the number of $P$. oceanica ground truth pixels as a function of two variables. Horizontal and vertical axes denote bathymetry and computed SDD, respectively and each matrix element is computed by counting the number of pixels falling into the related $1 \mathrm{~m} \times 1 \mathrm{~m}$ grid.

Although 17 pixels originate from 16-17 m depth grid, their SDDs do not exceed $12 \mathrm{~m}$. SDDs reach a

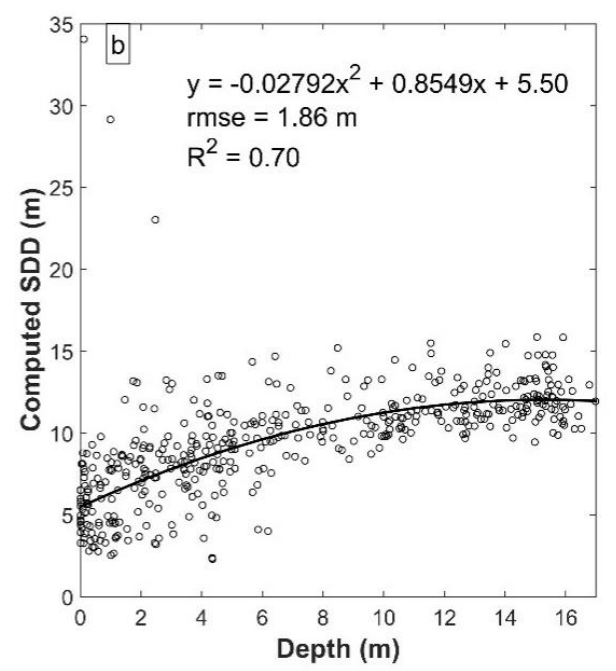

Figure 4. a) The relation between the Secchi Disk Depth (SDD) measurements and C2RCC-derived min(Kd), b) Computed SDDs vs bathymetric depths for 449 ground truth polygon centers.
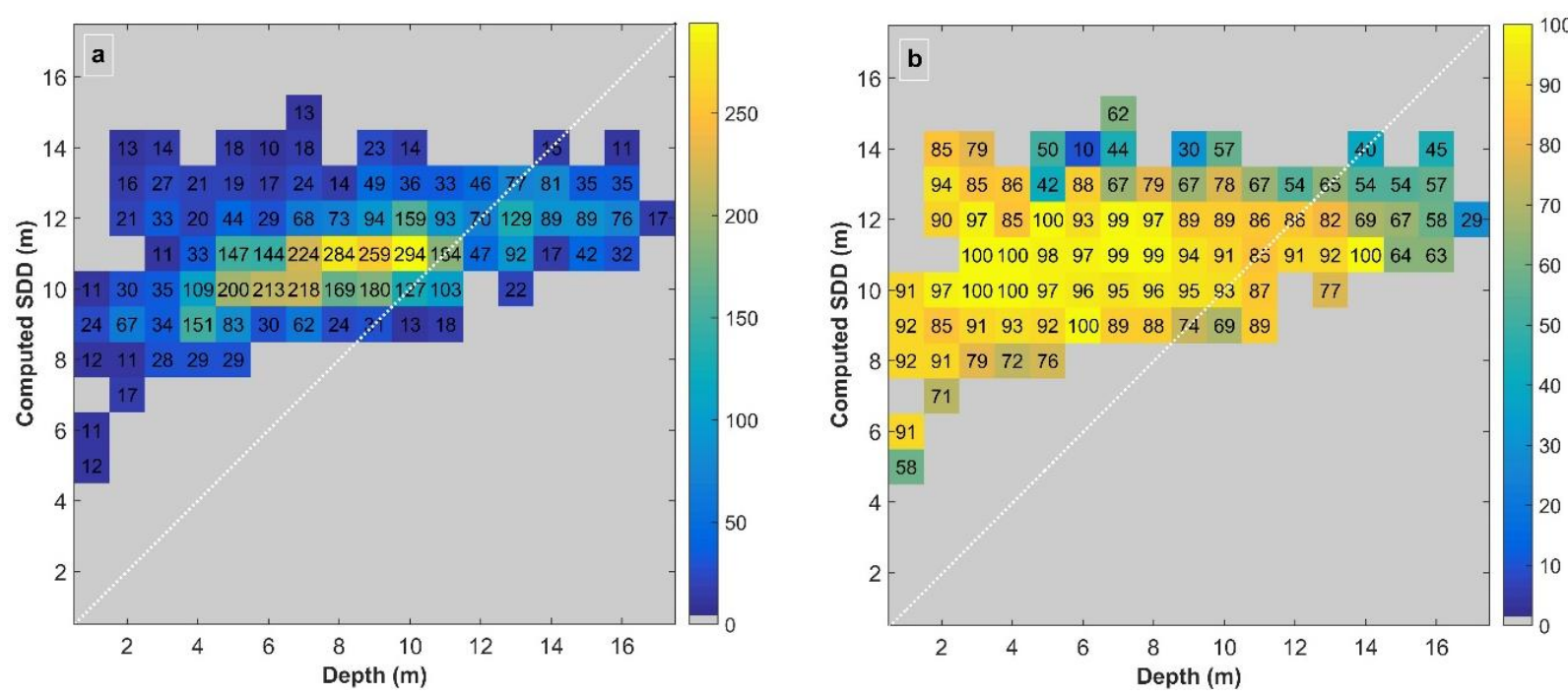

Figure 5. a) Color matrix showing the number and b) the TP percentages of the P. oceanica pixels in $1 \mathrm{~m}$ grid intervals. 
maximum value lower than $15 \mathrm{~m}$. The white diagonal line goes through the grids where the bathymetric depths and the SDDs are identical. Upper triangular offdiagonal elements host pixels having lower depth values than SDDs whereas lower triangular elements have larger depths than SDDs. $16 \%$ of all $P$. oceanica pixels belong to the lower triangle which is an indication of the diminishing reflectance from the bottom. The number of counts decreases by moving away from the diagonal to the right.

Figure5b displays TPs in each grid. The grid values represent percentages and were calculated by dividing the number of correctly classified pixels by the total number of pixels given in Figure5a. TPs at 2-14 $\mathrm{m}$ depth interval with $11 \mathrm{~m}$ SDD were obtained over $85 \%$. Similarly, the grid values at $12 \mathrm{~m}$ SDD varies between 85 and $100 \%$ from lower depths to $12 \mathrm{~m}$ and then descend to $29 \%$ at $17 \mathrm{~m}$ bathymetric depth. Grids with SDD values larger $12 \mathrm{~m}$ exhibit highly variable TPs.

\section{Discussion and Conclusions}

The ecosystem services provided by seagrass beds have been widely acknowledged in the Millennium Ecosystem Assessment (MEA). These include provisioning services, such as food, regulating services pertaining to atmospheric and climate regulation, waste processing, as well as protection from natural hazards such as floods, storms, and erosion, not to mention a series of cultural services (Duarte, C. M, 2000; Orth et al., 2006; Cullen-Unsworth \& Unsworth, 2013).

The study area was chosen on two grounds: first, the area contains natural monuments with three different types of meadows that call for urgent protection. The second, the socio-economic fact, that fisheries here are the mainstay of the local population. This is reflected by the existence of three Fishery Cooperatives that are currently active in the area Özbek, Gülbahçe and Balıklıova (Ünal, Göncüoğlu \& Yencan, 2009), whose total member number is 137 verbally confirmed by the president of the Fishery Cooperative Gülbahçe-Balıklıova, in addition to 600 individuals making a living from fishery related occupations (Tokac et al., 2010). In their studies of Jamaican seagrass meadows, Stoner (2003) and Behringer et al., (2009) have shown that the most abundant species landed in commercial fin-fish fisheries use seagrass meadows over various periods in their life cycles as their nursery and feeding habitats dictate. Similarly, our own field study of Gülbahce, pinpoints the commercial character of a number of species abundant in seagrass meadows (approximately 20 species).

The detailed map of $P$. oceanica in Gülbahçe bay was produced using multidisciplinary data acquisition methods. These include side-scan sonar imaging, subbottom profiler data, Worldview-2 satellite image, and in-situ data taken from diving (SCUBA and Snorkelling) and action camera images (Yücel-Gier et al., 2019). As a result of this study, a test area was created, and it was possible to compare with other seagrass meadows mapped in other Mediterranean countries.

In this study, raw Level $1 C$, atmospheric correction Level $2 \mathrm{~A}$ and DI composite images were classified with SVM. The use of DI composite did not increase accuracy, but atmospheric correction to the raw image was found to produce higher accuracy values. Discrepancies between the classification map and the ground truth map were mostly observed at the boundaries of $P$. oceanica covers. These boundary locations lie mainly on $P$. oceanica-soft bottom interfaces. The SVM classifier could not discriminate the $P$. oceanica pixels at these transition locations because their reflectance values resemble the non- $P$. oceanica pixels.

The largest samples came from SDDs of 10-11 m, nearly one-third of all $P$. oceanica ground truth pixels. $P$. oceanica pixels could be identified by the classifier effectively up to $13 \mathrm{~m}$ depth. The cover was detected from Sentinel-2 Level 2A image with $79.4 \%$ and $87.9 \%$ producer and user accuracies, respectively. Traganos \& Reinartz $(2018 a, b)$ reported better accuracies in their highly transparent test site where seagrasses were detected up to depths of $16.5 \mathrm{~m}$.

Light is a very important parameter for seagrass distribution. The lower limit of seagrasses depends on light conditions, turbidity, etc. (Collier, Lavery, Masini, \& Ralph, 2007; Ochieng, Short \& Walker, 2010). However, in accordance with the anthropogenic impact, the light reduces and this causes seagrass to diminish all around the world (Green \& Short, 2003). P. oceanica needs light for photosynthesis, and there is a direct relationship between the plants' access to light and their growth, survival and depth penetration (Kenworty \& Fonseca,1996). The depth for such plants and the light penetration as studied in different surveys and a Secchi disc determines how deep the plant can survive (Dennison et al., 1993).

The presence of $P$. oceanica in Figure $3 \mathrm{~b}$ appears to be more intense at a depth of 11-meter Secchi disc. Color matrix showing (5a) the number of $P$. oceanica pixels in 11 meters high. The depth was obtained to be $11.7 \mathrm{~m}$ and computed SDD changes from this point on very slowly despite a larger increase in the depth itself. Computed SDD increases by only $0.3 \mathrm{~m}$ and reaches 12.0 $\mathrm{m}$, at depth $17.0 \mathrm{~m}$ which is the $P$. oceanica limit value observed in the study area. Any reflectance from the depths greater than $11.7 \mathrm{~m}$ will be acquired not from the sea bottom but from the water column above it. The mapping using the satellite image also increases the opinion that using Secchi disk and sampling accordingly will speed up mapping process.

\section{Acknowledgements}

This study was supported by the IMST-DEU/BAP (Project no. 2014.KB.FEN.033). The authors thank Prof. Dr. E. Sayın for providing Secchi disc depth measurements. 


\section{References}

Akçalı, B., Kaboğlu, G., \& Güçlüsoy, H. (2019). A Review on Posidonia oceanica (Linnaeus) Delile Coverage Along the Turkish Coasts Until 2019. Journal of the Black Sea/Mediterranean Environment, 25(1), 115-124.

Alikas, K., \& Kratzer, S. (2017). Improved Retrieval of Secchi Depth for Optically-complex Waters Using Remote Sensing Data. Ecological Indicators, 77, 218-227. https://doi.org/10.1016/j.ecolind.2017.02.007

Alpar, B., Burak, S., \& Gazioğlu, C. (1997). Effect of weather system on the regime of sea level variations in Izmir Bay. Turkish Journal Marine Science, 3(2), 83-92.

Baker, E. K., \& Harris, P. T. (2012). Habitat Mapping and Marine Management. In: Seafloor Geomorphology as Benthic Habitat, (pp. 23-38). Elsevier,936 pp.

Behringer, D.C., Butler IV, M. J., Herrnkind, W. F., Hunt, J. H., Acosta, C. A., \& Sharp, W. C. (2009). Is Seagrass an Important Nursery Habitat for the Caribbean Spiny Lobster, panulirus argus, in Florida? New Zealand Journal of Marine and Freshwater Research,43(1), 327-337. https://doi.org/10.1080/00288330909510003

Boudouresque, C., Bernard, F., Bonhomme, G., Charbonnel, P., Diviacco, E., Meinesz, G., ... Tunesi, L. (2012). Protection and Conservation of Posidonia oceanica Meadows.RAMOGE and RAC/SPA, publisher Tunis 202pp.https://www.academia.edu/24386904/Protectio n_and_conservation_of_Posidonia_oceanica_meadows

Brockmann, C., Doerffer, R., Peters, M., Kerstin, S., Embacher, S., \& Ruescas, A. (2016). Evolution of the C2RCC Neural Network for Sentinel 2 and 3 for the Retrieval of Ocean Colour Products in Normal and Extreme Optically Complex Waters. Living Planet Symposium, 740, 54 pp.

Cancemi, G., De Falco, G., \& Pergent, G. (2003). Effects of Organic Matter Input from a Fish Farming Facility on a Posidonia oceanica meadow. Estuarine Coastal and Shelf Science, 56, 961-968. https://doi.org/10.1016/S02727714(02)00295-0

Collier, C. J., Lavery, P. S., Masini, R. J., \& Ralph, P. J. (2007). Morphological, growth and meadow characteristics of the seagrass Posidonia sinuosa along a depth-related gradient of light availability. Marine Ecology Progress Series, 337, 103-115.

https://doi.org/10.3354/meps337103

Cullen-Unsworth, L., \& Unsworth, R. (2013). Seagrass meadows, ecosystem services, and sustainability. Environment: Science and policy for sustainable development, 55(3), 14-28. https://doi.org/10.1080/00139157.2013.785864

Delgado, O., Ruiz, J., Pérez, M., Romero, J., \& Ballesteros, E. (1999). Effects of Fish Farming on Seagrass (Posidonia oceanica) in a Mediterranean Bay: Seagrass Decline After Organic Loading Cessation. Oceanologica. Acta, 22, 109117. https://doi.org/10.1016/S0399-1784(99)80037-1

Dennison, W. C., Orth, R. J., Moore, K. A., Stevenson, C. J., Carter, V., Kollar, S., ... Batiuk, R. (1993). Assessing Water Quality with Submersed Aquatic Vegetation: Habitat requirements as barometers of Chesapeake Bay Health.BioScience, 43(2), 86-94. https://doi.org/10.2307/1311969

Duarte, C.M. (2002). The future of Seagrass Meadows. Environmental Conservation, 29, 192- 206. https://doi.org/10.1017/S0376892902000127

Fornes, A., Basterretxea, G., Orfila, A., Jordi, A., Alvarez, A., \& Tintore, J. (2006). Mapping Posidonia oceanica from
IKONOS. ISPRS Journal of Photogrammetry and Remote Sensing, 60 (5), 315-322.

http://dx.doi.org/10.1016/j.isprsjprs.2006.04.002.

Fourqurean, W., Duarte, C.M., Kennedy, H., Marbà, N., Holmer, M., Mateo, M. A., ... Serrano, O. (2012). Seagrass Ecosystems as a Globally Significant Carbon Stock. Nature Geoscience, 5, 505-509. https://doi.org/10.1038/ngeo1477

Giannoulaki, M., Belluscio, A., Colloca, F., Fraschetti, S., Scardi, M., Smith, C., ...Spedicato, M. T. (2013). Mediterranean Sensitive Habitats. DG MARE Specific Contract SI2.600741, (FinalReport), Heraklion, $557 \mathrm{pp}$. https://www.coispa.it/docs/proj/MEDISEH\%20final.

Green, E., Mumby, P., Edwards, A., \& Clark, C. (2000). In J. E. Alasdair (Eds.), Remote Sensing: Handbook for Tropical Coastal Management., United Nations Educational, Scientific and Cultural Organization (UNESCO). Paris, 316 pp. https://unesdoc.unesco.org.

Green, E.P., \& Short, E.T. (2003). World Atlas of Seagrasses. Prepared by the UNEP World Conservation Monitoring Centre. University of California Press, Berkeley, USA.

Holmer, M., Perez, M., \& Duarte, C. M. (2003). Benthic primary producers-a neglected environmental problem in Mediterranean maricultures? Marine Pollution Bulletin, 46, 1372-1376. https://doi.org/10.1016/S0025326x(03)00396-5

Horning, N., Robinson, J.A., Sterling, E.J., Turner, W., \& Spector, S. (2010). Remote sensing for ecology and conservation: a handbook of techniques. Oxford University Press.

Hossain, M.S., Bujang, J.S., Zakaria, M.H., \& Hashim, M. (2014). The application of Remote Sensing to Seagrass Ecosystems: an Overview and Future Research Prospects.International Journal of Remote Sensing, 36, 61-114. http://dx.doi.org/10.1080/01431161.2014.990649.

Kanji, G.K. (2006). 100 Statistical Tests, Sage Publications, London.

IMST-199, (2017). Izmir Bay Oceanographic Monitoring Project. Final Report, Institute of Marine Sciences and Technology, Izmir, Turkey, 205p.

Kenworthy, W. J., \& Fonseca, M. S. (1996). Light Requirements of Seagrasses Halodule wrightii and Syringodium filiforme Derived from the Relationship Between Diffuse Light Attenuation and Maximum Depth Distribution. Estuaries and Coasts, 19(3), 740-750. https://doi.org/10.2307/1352533

Knudby, A., \& Nordlund, L. (2011). Remote Sensing of Seagrasses in a Patchy Multi-species Environment.International Journal of Remote Sensing, 32, 2227-2244. http://dx.doi.org/10.1080/ 01431161003692057.

Kostylev, V. E., Todd, B., Gordon, B.J.F., Courtney, R. C., Gordon, D. M., \& Pickrill, R. A. (2001). Benthic Habitat Mapping on the Scotian Shelf Based on Multibeam Bathymetry, Surficial Geology and Sea Floor Photographs. Marine Ecology Progress Series, 219, 121137. http://doi.org/10.3354/meps219121

Lyzenga, D.R. (1981). Remote Sensing of Bottom Reflectance and Water Attenuation Parameters in Shallow Water Using Aircraft and Landsat Data. International journal of remote sensing, 2(1), 71-82. https://doi.org/10.1080/01431168108948342

Matta, E., Aiello, M., Bresciani, M., Gianinetto, M., Musanti, M., \& Giardino, C. (2014). Mapping Posidonia Meadow 
from High Spatial Resolution Images in the Gulf of Oristano (Italy). IEEE International Symposium, Quebec City, 5152-5155 pp. http://dx.doi.org/10.1109/IGARSS.2014.6947658

RTMAF. (Republic of Turkey Ministry of Agriculture and Forestry) (2016). The notification of Regulation of Amateur Purpose Fisheries Hunting Turkish Official Gazette No., 36.

Mobley, C. D. (1994). Light and Water: Radiative transfer in natural waters. Academic Press, Cambridge, MA.

Nordlund, L. M., Koch, E. W., Barbier, E. B., \& Creed, J. C. (2016). Seagrass ecosystem services and their variability across genera and geographical regions. PLoS One, 11, 123. https://doi.org/10.1371/ journal.pone.0163091

Nordlund, L. M., Unsworth, R. K. F., Gullström, M., \& CullenUnsworth, L. C. (2017). "Global significance of seagrass fishery activity." Fish and Fisheries, 19 (3), 399-412. https://doi.org/10.1111/faf.122590chieng, C. A., Short F. T., \& Walker, D. I. (2010). Photosynthetic and morphological responses off eelgrass (Zostera marina L.) to gradient of light conditions. Journal of Experimental Marine Biology and Ecology, 382, 117-124. https://doi.org/10.1016/j.jembe.2009.11.007

Orth, R.J., Carruthers, J. B., Duarte, C.M., Fourqurean, J. W., Heck, K.L., Hughes, A. R., ... Williams, S. L. (2006). A global crisis for seagrass ecosystems. Bioscience, 56, 987-996. https://doi.org/10.1641/00063568(2006)56[987:AGCFSE]2.0.CO;2

Pasqualini, V., Pergent-Martini, C., Pergent, G., Agreil, M., Skoufas, G., Sourbes, L., \& Tsirika, A. (2005). Use of SPOT 5 for mapping seagrasses: an application to Posidonia oceanica. Remote Sensing of Environment, 94, 39-45. https://doi.org/10.1016/j.rse.2004.09.010

Pergent, G., H. Bazairi, C. N. Bianchi, C. F. Boudouresque, M. C. Buia, P. Clabaut, M. Harmelin-Vivien, ... Verlaque, M. (2012). Mediterranean Seagrass Meadows: Resilience and Contribution to Climate Change Mitigation, A Short Summary, Gland, Switzerland and Málaga, Spain: IUCN,40 pp.

Pergent, G. (2006). Le rôle des herbiers à Posidonia oceanica. In : "Préservation et conservation des herbiers à Posidonia oceanica » Boudouresque, C. F., Bernard, G., Bonhomme, P., Charbonnel, E., Diviacco, G., Meinesz, A., Pergent, G., ... Tunesi, L., (Eds.), Ramoge publ., 48-60.

Piazzi, L., Acunto, S., \& Cinelli, F. (2000). Mapping of Posidonia oceanicaBeds Around Elba Island (western Mediterranean) with Integration of Direct and Indirect
Methods. Oceanologica Acta, 23(3), 339-346. https://doi.org/10.1016/S0399-1784(00)00132-8

Poursanidis, D., Traganos, D., Reinartz, P., \& Chrysoulakis, N. (2019). On the Use of Sentinel-2 for Coastal Habitat Mapping and Satellite-Derived Bathymetry Estimation Using Downscaled Coastal Aerosol Band. International Journal of Applied Earth Observation and Geoinformation, 80, 58-70.

https://doi.org/10.1016/j.jag.2019.03.012

Richards, J.A. (2013). Remote Sensing Digital Image Analysis: an Introduction, 5th ed. Springer. Berlin Heidelberg.

Stoner, A.W. (2003). What Constitutes Essential Nursery Habitat for a Marine Species? A Case Study of Habitat Form and Function for Queen Conch. Marine Ecology Progress Series, 257, 275-289.

http://doi.org/10.3354/meps257275

Tokac A., Ünal V., Tosunoğlu Z., Akyol O., Özbilgin H., \& Gökce G. (2010). Ege Denizi Balıkçılığı. IMEAK Deniz Ticaret Odası Izmir Subesi Yayınları, Izmir, 390 pp.

Traganos, D., \& Reinartz, P. (2018a). Mapping Mediterranean Seagrasses with Sentinel-2 Imagery. Marine Pollution. Bulletin, 134, 197-209. https://doi.org/10.1016/j.marpolbul.2017.06.075

Traganos, D., \& Reinartz, P. (2018b). Machine Learning-Based Retrieval of Benthic Reflectance and Posidonia oceanica Seagrass Extent Using a Semi-analytical Inversion of Sentinel-2 Satellite Data. International Journal of Remote Sensing, 39(24), 9428-9452. https://doi.org/10.1080/01431161.2018.1519289

Ünal, V., Göncüoğlu, H., \&Yercan, M. (2009). Ege Kıyıları Su Ürünleri Kooperatifleri, SÜRKOOP-Su Ürünleri Kooperatifleri Merkez Birliği Yayınları, Yayın No:1 ISBN:978-605-60880-0-1, Ankara, 131 pp.

UNEP. (2012). Action plan for the conservation of marine vegetation in the Mediterranean Sea, Tunis, pp.9.http://www.rac-spa.org.

van der Linden, S., Rabe, A., Held, M., Jakimow, B., Leitão, P. J., Okujeni, A., ... Hostert, P. (2015). TheEnMAP-Box-A toolbox and application programming interface for EnMAP data processing. Remote Sensing, 7(11), 1124911266. https://doi.org/10.3390/rs70911249

Yücel-Gier, G., Koçak, G., Akçalı, B., IIlhan, T., \& Duman, M. (2019). Mapping of Posidonia oceanica (L.) Delile in the bay of Gülbahçe. Proceedings of the Mediterranean Symposium on Marine Vegetation. Antalya, Turkey, 98102. 